\title{
Characteristics of Confrontation Naming Ability according to Word Frequency in Patients with Amnestic Mild Cognitive Impairment: A Preliminary Study
}

\author{
Sae Rom Won", Ji Hye Yoon ${ }^{\mathrm{b}}$, Duk L. Na \\ ${ }^{a}$ Department of Speech-Language Pathology, Graduate School of Hallym University, Chuncheon, Korea \\ ${ }^{b}$ Department of Speech-Language Pathology and Audiology, Graduate School of Hallym University, Chuncheon, Korea \\ 'Department of Neurology, Samsung Medical Center, Sungkyunkwan University School of Medicine, Seoul, Korea
}

\author{
Correspondence: Ji Hye Yoon, $\mathrm{PhD}$ \\ Department of Speech Pathology and Audiology, \\ Hallym University, 1 Hallimdaehak-gil, Chuncheon \\ 24252, Korea \\ Tel: $+82-33-248-2224$ \\ Fax: +82-33-256-3420 \\ E-mail: j.yoon@hallym.ac.kr
}

Received: April 5, 2017

Revised: May 17, 2017

Accepted: May 25, 2017

This research was supported by 2017 Hallym University Research Fund (No. HRF-201704-011).

This material is based upon work supported by the Ministry of Trade, Industry \& Energy (MOTIE) of Korea under Industrial Technology Innovation Program (No. 10063384).

This work was supported by the National Research Foundation of Korea grant funded by the Korean government (No. NRF-2014S1A5A2A03065709).

\begin{abstract}
Objectives: Characteristics of word finding difficulty due to cognitive decline may be influenced by word frequency. We investigated the characteristics of confrontation naming ability of mild cognitive impairment $(\mathrm{MCl})$ patients according to word frequency and examined the relationship between overall cognitive function and confrontation naming ability. Methods: We performed Korean version of Boston Naming Test (K-BNT) and a low frequency word naming task (Difficult Naming Test, DNT) in 40 normal elderly and 35 amnestic-MCl (aMCl) patients. In both tasks, response scores to each item and the type of errors in low frequency word naming tasks between the two groups were analyzed. In addition, we analyzed the correlation between Korea version of Mini-Mental Status Examination (K-MMSE) scores and K-BNT scores and DNT scores. Results: First, the aMCl group showed significantly lower performance in all tasks than the normal elderly group. Both groups showed lower scores in the DNT than in the K-BNT, but these differences in performance were greater in the aMCl group. Second, aMCl group showed a significantly higher ratio of semantic error, visual errors, and non-related errors. Third, there was a statistically significant correlation between the K-MMSE scores and the DNT scores in the aMCl group. Conclusion: High frequency words are strong and stable in representations stored in the semantic system, but low frequency words usually have weaker intensity of semantic representation. Therefore, they may be more sensitive indicators of the neurological changes of aMCl. In terms of clinical application, DNT can be used to identify and distinguish functional decline in individuals with $\mathrm{aMCl}$.
\end{abstract}

Keywords: Mild cognitive impairment, Confrontation naming, Low frequency word
치매의 가장 흔한 원인 질환은 전체에서 약 $72 \%$ 를 차지한 '알츠 하이머병'(Alzheimer's disease, $\mathrm{AD}$ )인 것으로 나타났다(Health Insurance Review \& Assessment Service, 2016). AD는 병세가 점진 적으로 진행되는 퇴행성 질환으로 증상이 경미한 전임상적(preclinical) 단계에서 위험군을 조기에 발견하고 치료를 통해 병의 진 행을 지연시키고 예방하는 것이중요하다(Ritchie, \& Touchon, 2000).

정상 노화와 $\mathrm{AD}$ 의 중간 혹은 전이단계(transitional state)로 여
겨지는 경도인지장애(mild cognitive impairment, $\mathrm{MCI}$ )는 매년 $10 \%-15 \%$ 가 $\mathrm{AD}$ 로 진행되며, 6년 이내에 $80 \%$ 가 $\mathrm{AD}$ 로 전이되므로 치매의 고위험군으로 간주된다. $\mathrm{MCI}$ 는 집단 내 이질성으로 인해 임상적 양상에 따라 4가지 하위집단으로 나눌 수 있는데, 먼저 기 억장애의 여부에 따라 기억성(amnestic $\mathrm{MCI}, \mathrm{aMCI})$ 과 비기억성 (non-amnestic MCI, naMCI)으로 구분되며, 기억성의 경우 기억력 만 손상된 기억성 단일 영역 $\mathrm{MCI}$ (amnestic $\mathrm{MCI}$ single domain, a- 
MCI-single domain)와 기억력 외에 다른 인지기능의 손상을 함께 보이는 기억성 중다 영역 $\mathrm{MCI}$ (amnestic MCI multiple domain, aMCI-multiple domain)로 분류된다. 비기억성의 경우 기억력 외 다 른 인지기능의 한가지 영역에서 손상을 보이는 비기억성 단일 영역 (non-amnestic MCI single domain, na-MCI-single domain)과 기 억력 외 여러 인지기능에서 손상을 보이는 비기억성 중다 영역(nonamnestic MCI multiple domain, na-MCI-multiple domain)으로 분류된다(Petersen, 2003). 증상이 경미한 전임상적(preclinical) 단 계에서 $\mathrm{AD}$ 로 진행할 가능성이 있는 위험군을 조기에 발견하고 진 단 및 적극적인 치료를 통해 병의 진행을 지연시키고 예방하는 것 은 의료의 임상적 적용과 사회경제적 기회비용의 측면에서 중요한 쟁점이 된다(Ritchie, \& Touchon, 2000). 따라서 MCI의 네 가지 하 위유형 중 $\mathrm{AD}$ 로 진행될 가능성이 가장 높은 위험군으로 보고된 (Petersen et al., 1999) aMCI에 대하여 주목할 필요가 있다.

$\mathrm{MCI}$ 는 초기 $\mathrm{AD}$ 환자와 유사하게 의미적 측면에서의 저하를 두 드러지게 보인다(Adlam, Bozeat, Arnold, Watson, \& Hodges, 2006;

Duong, Whitehead, Hanratty, \& Chertkow, 2005; Petersen et al., 1999)는 점에서 $\mathrm{MCI}$ 의 언어적 특성에 관한 선행연구들은 주로 의 미기억(semantic memory)에 초점을 두고 진행되었다. 여기서 의미 기억이란 사람, 사물, 장소 등의 개념과 이름, 의미 등에 대한 영구적 인 지식을 포함하고 있기에, 객체를 정확히 확인하고 그에 맞는 이 름을 말하며, 구어와 문어를 이해하고 언어를 산출하는 데 필수적 인 요소가 되기도 한다(Hodges, Salmon, \& Butters, 1992). 따라서 의미적 측면의 언어 손상을 보이는 $\mathrm{MCI}$ 환자에게서 가장 흔히 발 견되는 특징은 적절한 단어를 산출해내는 이름대기에서의 어려움 이다(Adlam et al., 2006; Petersen et al., 1999; Willers, Feldman, \& Allegri, 2008). 이름대기 장애는 정확한 단어를 적절한 시점에 산 출하지 못하게 하며, 대용어를 사용하게 되면서 정보전달 능력이 저하되는 양상으로 이어지게 된다(Joubert et al., 2010). 그간의 선 행연구에서는 이러한 이름대기의 결함을 의미기억(semantic memory) 자체의 손상 때문이거나(Martin, \& Fedio, 1983), 의미기억 자 체의 손상 보다는 의미기억에 접근하는 과정의 손상이거나(Nebes, 1989), 의미적 자질들에 부합하는 단어를 어휘체계(lexical system) 로부터 인출해 내는 과정이 손상된 것이라는 가설(Chenery, Murdoch, \& Ingram, 1996; Duong et al., 2006) 등으로 설명하고자 하였 다. 이 외에 $\mathrm{MCI}$ 는 형태 및 구문적 측면에서는 동사, 형용사 등 활 용어의 어간 변형 시 생략 혹은 대치의 오류를 많이 보이며(Altmann, Kempler, \& Andersen, 2001), 화용 측면에서는 문맥상 중요한 사건을 설명하는데 어려움을 보이기도 한다(Heller, Dobbs, \& Rule, 1992).

치매의 초기 단계부터 대면이름대기 과제(confrontation naming test)에서의 수행력 저하가 보고되면서(Balthazar, Cendes, \& Damasceno, 2008; Duong et al., 2006; Jefferson et al., 2007) 정상과 구별 되는 $\mathrm{MCI}$ 환자들의 이름대기 능력을 확인하기 위한 도구로서 대면 이름대기과제가 많이 활용되었다. 그러나 그동안 보고된 대면이름 대기과제를 사용하여 $\mathrm{MCI}$ 의 이름대기 수행력을 확인한 선행연구 들을 살펴보면 서로 상반되는 결과가 혼재되어 있는 것을 확인할 수 있다. 정상 노인과 $\mathrm{MCI}$ 가 대면이름대기과제에서 유의한 차이를 보였다고 보고하는 연구(Balthazar, Cendes, \& Damasceno, 2008; Duong et al., 2006; Jefferson et al., 2007; Johns et al., 2012; Mioshi, Dawson, Mitchell, Arnold, \& Hodges 2006; Woo, \& Kim, 2015)가 있는 반면에, 두 집단의 수행력이 유사하다고 보고한 경우도 있다 (Adlam et al., 2006; Beinhoff, Hilbert, Bittner, Grön, \& Riepe, 2005; Choi, Kim, Lee, \& Kim, 2013; Griffith et al., 2006; Guo, Zhou, Zhao, Wang, \& Hong, 2012; Price et al., 2010). 이렇게 상충되는 결과가 서 로 혼재하는 이유로는 먼저 연구대상자에 포함된 $\mathrm{MCI}$ 의 특성이 연구마다다르기 때문으로 해석할 수 있다. 이미 언급하였듯이 MCI 는 하위유형에 따라 언어장애의 정도가 서로 다를 수 있다. 이와 더 불어 선행연구에서 사용된 대면이름대기검사의 문항 개수의 차이 가 결과에 영향을 미쳤을 가능성도 배제할 수 없다. 초기에 고안된 이름대기 검사의 원본 그대로의 항목을 모두 포함하는지 일부 항 목을 추출한 단축형을 사용하였는지에 따라 결과가 상이할 수 있 는 것이다. 이에 Hwang과 Kim (2014)은 메타분석을 통하여 서로 다른 표본크기나 검사문항의 차이를 출판 편향으로 보정하고 종합 적인 결론을 도출하는 방식으로 대면이름대기검사가 정상군과 $\mathrm{MCI}$ 의 변별에 유용하게 사용될 수 있음을 증명하였다. 더불어 저 자들은 보다 변별력이 높은 문항으로 추출된 단축형의 이름대기검 사가 임상에서 감별 진단 도구로 활용될 수 있는 가능성 또한 제시 하였다. 이렇듯 변별력을 증가시키기 위해서 연구자들은 기존의 검 사항목에서 문항반응이론을 적용하여 변별력이 높은 문항을 추출 하기도 하고(Kim, \& Kim, 2013) 천장효과를 제거하면서 다소 비친 숙한 항목만으로 구성된 검사를 시행하기도 한다(Mioshi et al., 2006).

단어의 빈도는 이름대기에 영향을 미칠 수 있기 때문에(Burke \& Shafto, 2004) Mioshi 등(2006)은 aMCI와 정상군을 대상으로 Addenbrooke's Cognitive Examination (ACE; Mathuranath et al., 2000)의 대면이름대기과제를 실시하였다. 그리고 대상자의 반응 중 저빈도 단어 12 개에 대한 수행력을 비교하는 방식으로 저빈도 단어 이름대기과제 또한 두 군의 특성을 감별해줄 수 있음을 보여 주었으며, $\mathrm{MCI}$ 에서 관찰될 수 있는 의미어휘적 정보에 대한 활성 화 감퇴가 저빈도 단어에서 더 빈번히 나타남을 주장하였다(Gar- 
rard, Maloney, Hodges, \& Patterson, 2004). 한편 MCI의 이름대기 능력에 관한 선행연구는 정상인과의 비교뿐만 아니라 $\mathrm{AD}$ 와의 비 교를 통해서도 이루어졌는데(Duong et al., 2006), 어휘와 관련된 다양한 과제를 시행하였을 때 $\mathrm{AD}$ 는 모든 난이도의 과제에서 수행 력의 저하를 보였으나 $\mathrm{MCI}$ 는 상대적으로 어려운 난이도의 항목이 포함되어 있는 과제에서만 수행력 저하를 보였다. 이는 $\mathrm{AD}$ 로 진행 하는 과정에서 의도적이고/노력을 필요로 하는 어려운 난이도의 처리과정이 쉬운 난이도의 자동적인 처리과정보다 더 초기에 손상 될 수 있음을 보여준다. 따라서 이러한 선행연구의 결과는 단어 빈 도와 같이 다양한 난이도의 과제를 통해 $\mathrm{MCI}$ 의 이름대기 특성을 관찰하는 것이 $\mathrm{MCI}$ 의 조기예방이나 감별진단 및 중재에 있어서 임상적 근거로 제공되고 활용될 수 있음을 시사한다.

이렇듯 단어의 빈도에 따른 이름대기 특성을 확인하는 측면에서 상기의 선행연구(Mioshi et al., 2006)는 저빈도 단어 문항을 활용 하는 시도를 하였으나 표준화된 검사도구 내에서 소수의 문항만을 추출하여 그 수행력을 살펴보았으므로 저빈도 단어를 충분히 포함 한 체계적 연구(systematic study)가 이루어지지 않았을 가능성이 있다. 또한 다양한 스펙트럼의 인지장애를 확인하기 위해 표준화된 검사도구의 본래 목적상 검사문항의 상대적 난이도에 따라 저빈도 로 간주되었으나 실제로는 저빈도가 아닌 문항이 12항목 내에 포함 되었을 수 있다.

이와 더불어, MCI나 치매를 대상으로 한 선행연구에서 대면이 름대기과제가 가진 특성에 주목하여 그 반응의 산물인 오류를 분 석하는 작업도 진행하였다. Ellis와 Young (1988)의 모델에 따르면, 대면이름대기의 과정은 먼저, 사물의 외형에서 얻어지는 시각적 정 보만으로 사물을 인식하게 되고, 그렇게 인식된 사물의 용도나, 특 징, 개념과 같은 지식이 저장된 의미적 체계를 거쳐 어휘 체계에서 그 특정한 의미와 연결된 어휘를 선택하게 된다. 선택된 어휘의 음 운적 표상이 저장된 음운산출체계에 도달하면 비로소 사물의 이 름을 산출하게 된다. 따라서 상기와 같은 경로 중 어느 단계가 손상 되었는지에 따라 나타나는 오류가 다를 수 있다(Balthazar er al., 2008)는 점에서 오류 분석은 정오반응 여부와 함께 이름대기의 특 성을 살펴볼 수 있는 좋은 분석법이 된다. 특정 오류가 특정 단계의 손상을 반드시 의미하는 것은 아니지만 의미적으로 연관된 오류 는 의미적 단계의 손상으로 나타날 수 있으며, 음소착어 등과 같은 음운적 오류는 음운론적 단계의 손상으로 나타날 수 있다(Caramazza \& Hillis, 1990). 이러한 맥락에서 Willers 등(2008)은 보스 톤 이름대기검사(Boston Naming Test)를 사용하여 $\mathrm{AD}$ 집단과 $\mathrm{aMCI}$ 집단은 정상노인 집단보다 의미적 연관 오류를 유의하게 많 이 보이고, $\mathrm{AD}$ 집단은 $\mathrm{aMCI}$ 집단보다 답을 모르거나 무응답을 하
는 양상이 빈번하였음을 보고하였다. 한국판 보스톤이름대기검사 (Korean version-Boston Naming Test, K-BNT; Kim \& Na, 1997)를 사용하여 정상노인, $\mathrm{AD}$ 의심군, 경도의 $\mathrm{AD}$, 중등도의 $\mathrm{AD}$ 네 집단 을 비교한 연구(Kim, Kim, \& Na, 1997)에서는 정상노인 집단과 $\mathrm{AD}$ 의심군 집단이 중등도의 $\mathrm{AD}$ 집단에 비하여 유의하게 많은 의 미적 연관 오류를 보였으며 비연관 오류와 시지각 오류의 경우에는 병의 중증도가 심해질수록 유의하게 증가하는 양상을 보고하였다.

따라서, 본 연구는 단어 빈도에 따른 $\mathrm{aMCI}$ 의 대면이름대기 수행 특성을 확인하기 위한 예비연구로서 고빈도에서 저빈도를 모두 포 함하면서 표준화된 이름대기검사 도구인 K-BNT와 저빈도 단어만 으로 구성된 이름대기 과제(Na \& Yoon, in press)를 모두 시행하였 다. 그리고 정상통제군과의 비교를 통하여 $\mathrm{aMCI}$ 집단이 단어 빈도 에 따라 대면이름대기 수행력이 어떻게 달라지는지를 관찰하고, 저 빈도 단어 과제에서 관찰되는 이름대기 오류 유형을 확인하였다. 더불어 저빈도 단어에 대한 이름대기 장애가 $\mathrm{MCI}$ 의 의미어휘적 능 력의 감퇴뿐만 아니라 전반적인 인지기능과 어떠한 관련이 있는지 를 확인하기 위하여 단어 빈도에 따른 대면이름대기 과제 수행과 인지기능 선별검사와의 상관관계를 살펴보았다.

\section{연구방법}

\section{연구대상}

본 연구는 만 60-85세의 정상노인 40 명과 $\mathrm{aMCI}$ 환자 35 명인 총 75 명을 연구대상으로 하였다. 연령의 범위를 60 세 이상으로 한정한 이유로는 국민연금법(2017)에서는 60세 이상, 노인복지법(2015)에 서는 65 세 이상을 각각 노인이라 규정하고 있으므로 둘 중 더 넓은 범위를 포괄하는 기준에 따라 60 세 이상으로 선정하였다. 정상노 인의 선정기준은 다음과 같다. (1) 건강선별설문지(Christensen, Multhaup, Nordstrom, \& Voss, 1991)를 실시하여 신체기능이 정상 으로 판단되는 자, (2) 단축형 노인우울척도(Short form Geriatric Depression Scale, SGDS; Ki, 1996)에서 8점 이하로 우울감이 없으 며, (3) 한국판 간이정신상태검사(K-MMSE; Kang, Na, \& Hahn, 1997) 점수가 연령과 학력에 기초하여 $16 \%$ ile 이상으로 정상규준 (Kang, 2006)에 해당하는 노인으로 선정하였다. $\mathrm{aMCI}$ 환자는 종 합병원 신경과 전문의로부터 Petersen (2004)의 진단기준에 따라 기억성(amnestic) $\mathrm{MCI}$ 로 진단된 대상자로 세부적인 진단기준은 다음과 같다. (1) 환자나 보호자에 의한 주관적인 기억장애 호소가 있고, (2) K-MMSE 점수가 -1.0 SD 이상으로 전반적인 인지 기능은 정상 범위에 속하고, (3) S-IADL (Seoul-Instrumental Activities of Daily Living; Ku et al., 2004)에서 8점 미만이며, (4) SNSB (Seoul 
Neuropsychological Screening Battery; Kang \& Na, 2003)검사 결 과 연령 및 교육년수에 해당하는 규준에서 언어적 기억력검사(Seoul Verbal Learning Test, SVLT)의 지연회상(delayed recall) 점수 또는 비언어적 기억력을 확인하는 Rey Figure Test의 지연회상(delayed recall)점수가 $16 \%$ ile 미만이며, (5) 치매의 기준에는 해당하지 않는 자를 대상으로 하였다. 또한 본 연구대상이 기억성 단일영역뿐만 아니라 기억성 중다영역의 MCI도 포함하는 것으로 하였기 때문에 이를 위해서 위의 조건을 모두 만족하면서 주의집중력 언어능력, 시공간기능, 전두엽 기능 등의 인지기능들 중 한 가지 이상의 인지 기능 저하를 보이는 경우도 포함하였다. 집단 간 연령 $(t=-1.769$, $p>.05)$ 및 교육년수 $(t=.242, p>.05)$ 는 통계적으로 유의한 차이를 보이지 않았으나, K-MMSE 점수는 집단간차이가 유의한 것으로 나 타났다 $(t=4.285, p<.05)$. 대상자의 배경정보는 Table 1 에 제시하였다.

\section{자료수집 도구}

자료수집에는 총 두 가지 과제가 사용되었다. 먼저, 신경언어장 애 환자군의 대면이름대기능력 평가에 가장 많이 사용되고 있는 표준화된 도구인 K-BNT (Kim \& Na, 1997)를 사용하여 전반적인 대면이름대기 능력을 측정하였다. K-BNT는 고빈도 단어에서부터 저빈도 단어까지의 다양한 빈도로 이루어져 있으며, 총 60 개의 흑 백의 선 그림으로 구성되어 있다. 이와 더불어 어려운 단어로 구성 된 저빈도 단어 이름대기검사(Difficult Naming Test, DNT; Na \& Yoon, in press)를 사용하였다. 이 과제는 다음과 같은 단계를 통해 제작되었다. 먼저, 단어 선정을 위해 '한국어 구어 빈도사전'(Seo, 2015)과 국립국어원의 '현대 국어 사용 빈도 조사'(Jo, 2002)를 참조 하였으며, Hwang (2013)의 저빈도 단어 선정 기준을 참고하여 전 체 빈도 30 이하에 해당되면서 그림으로 표현이 가능한 100 개의 단 어를 우선 선정한 후에, 흑백의 선으로 이루어진 그림카드로 제작 하였다. 본 연구진을 포함하여 치매환자 진단 경험이 있는 전문의 2 명이 그려진 그림이 적절한가에 대하여 확인하였으며, 동시에 50세 이상의 정상 성인 10 명에게 보여주고 그림의 적절성에 대한 의견을 취합하였다. 그 후 검사시간에 따른 피험자의 피로도가 문항에 미

Table 1. Participants' characteristics

\begin{tabular}{lll}
\hline & \multicolumn{1}{c}{$\mathrm{NE}(\mathrm{N}=40)$} & \multicolumn{1}{c}{ aMCl $(\mathrm{N}=35)$} \\
\hline Age (yr) & $71.27 \pm 5.79(60-85)$ & $73.65 \pm 5.84(60-85)$ \\
Education (yr) & $11.62 \pm 4.01(6-18)$ & $11.53 \pm 4.89(0-18)$ \\
K-MMSE & $28.11 \pm 1.85(24-30)$ & $25.80 \pm 2.93(18-30)$
\end{tabular}

Values are presented as mean $\pm S D$ (range).

$\mathrm{NE}=$ normal elderly; $\mathrm{aMCl}=$ amnestic-mild cognitive impairment; $\mathrm{K}-\mathrm{MMSE}=$ Korean version of Mini-Mental State Examination (Kang, Na, \& Hahn, 1997).
칠 수 있는 영향을 최소화 하고자 100 개 단어의 순서를 무작위로 배열한 검사기록지를 3 가지 유형으로 제작하였다. 그리고 본 실험 에 참여하지 않는 정상노인 30 명(mean age $=65.8$ 세, mean education=11.6년, Gender $=$ Male 13, Female 17)에게 각 검사기록지당 10 명씩 할당하여 대면이름대기검사를 실시하였다. 이름대기검사 시 대상자에게 '지금부터 여러 가지 그림들을 보여드리겠습니다. 잘 보시고 각 그림들의 이름을 말씀해주시면 됩니다.'라는 지시와 함께 연습문항을 실시한 후 검사를 시행하였으며, 이때 검사시간 은 약 20-30분 정도 소요되었다. 그렇게 얻어진 100 개의 단어에 대 한 응답 결과를 문항곤란도로 산정하여 곤란도가 높은 쉬운 문항 부터 곤란도가 낮은 어려운 문항 순으로 배열한 후, 그림이 모호하 게 표현되어 대상자들이 그림이 의도하는 바를 명확하게 파악하지 못하는 경우와 다수의 응답이 도출되는 경우를 제외하였고 각각의 문항과 전체검사 간의 상관관계 분석을 통하여 부적절한 문항을 제외시켰다. 이러한 과정을 통하여 문항곤란도가 1 에서 0.1 까지 고 루 분포되도록 최종 60 문항을 선정하였으며(Appendix 1), 60항목 에 대한 내적일관성 신뢰도값(Cronbach's a 계수)은 .945로 신뢰도 가 높았다. 60 항목의 순서는 응답 결과를 원칙으로 하되 연이어 제 시되는 자극문항이 음소적으로 연관성을 보이는 경우에는 전후 배 열을 약간씩 수정하였다.

\section{자료수집 절차}

본 검사는 조용하고 독립된 공간에서 개별적으로 진행되었다. 과 제 시행에 앞서 연구에 참여한 모든 대상자에게 연구의 목적과 과 제를 충분히 설명하고 자발적인 의지에 의한 참여 및 동의 여부를 확인한 뒤 설문조사를 통하여 대상자의 나이, 성별, 교육년수, 병력 에 관한 기본 정보를 수집하였다. 자세한 검사 절차는 다음과 같다. 먼저, 표준화된 검사도구인 K-BNT의 검사를 실시하였다. 검사 전 대상자에게 “지금부터 여러 가지 그림들을 보여드리겠습니다. 잘 보시고 각 그림들의 이름을 말씀해 주세요. 어떤 문항들은 매우 쉽 지만 어떤 문항들은 상당히 어려울 수도 있습니다. 준비되셨으면 시작하겠습니다.”라는 지시사항을 전달한 뒤, 60개의 그림을 하나 씩 보여주었고, 환자의 반응은 동시에 현장에서 검사 기록지에 기 록하였다. K-BNT 실시 후, 저빈도 단어 이름대기과제(Na \& Yoon, in press)를 실시하였다. 시작 전 대상자에게 “지금부터 보여드릴 그 림들은 평소에 자주 사용하지 않는 저빈도의 단어들로 이루어져 있기 때문에 어려울 수도 있습니다. 잘 보시고 각 그림들의 이름을 말씀해주세요. 준비되셨으면 시작하겠습니다.”라는 지시사항을 전 달한 뒤, 과제를 시작하였다. Brookshire (1970)의 연구결과에 준하 여 대상자가 15 초가 지난 후에도 반응하지 않는다면 다음 문항으 
로 넘어갔다. 검사 시 관찰된 대상자의 반응을 자세히 분석하기 위 하여 반응을 ‘소니 ICD-PX240’ 녹음기로 녹음하였으며, 동시에 현 장에서 연구자가 검사 기록지에 반응을 기록하였다. 본 연구의 모든 연구 절차는 한림대학교(HIRB-2016-088)와 삼성서울병원(201602-030)의 임상연구윤리위원회의 승인을 받았다.

\section{자료분석}

K-BNT는 전문가 지침서에 근거하여 대상자가 15 초 이내에 자발 적으로 정확한 목표어휘를 산출한 경우 정반응으로 처리하였으며, 어휘를 산출하는 과정에서 자가수정(self-correction)을 보인 경우 마지막 반응을 답으로 간주하였다. 정반응한 문항은 1 점으로 총점 60 점 만점이다. 저빈도 단어 이름대기과제에 대한 대상자의 반응은 ‘정반응수’와 ‘오류 유형'으로 나누어 채점하였다. 대상자가 15초 이 내에 자발적으로 그림에 해당하는 정확한 목표어휘를 산출한 경우 를 정반응으로 처리하며, 다른 어휘를 산출하거나 다음 문항으로 넘어간 뒤에 앞 문항의 목표어휘를 산출하는 경우는 오반응으로 처리하였다. 또한, 방언으로 답하는 경우에는 국립국어원의 표준 국어대사전에 목표어휘의 방언으로 등록이 된 경우만 정반응으로 처리하며(예: 두레박-두룸박, 뒤주-뒤지, 절구-도구통, 탈곡기-홀태, 등), 자가수정을 하였을 경우에는 마지막 반응으로 결과를 분석하 였다. 정반응한 문항은 1점으로 총점 60 점 만점이다. 오류 유형에 대한 분석기준은 Kim, Pae, Park과 Shin (2002), Kim 등(1997) 그 리고 Balthazar 등(2008)의 연구를 참고하여 수정, 보완하였다(Appendix 2).

\section{신뢰도}

오류 유형 분류에 대한 신뢰도를 검증하기 위해 전체 대상자의 $20 \%$ 에 해당하는 자료를 무작위로 추출하여 검사자 간 신뢰도를 분석하였다. 이를 위해 언어병리학을 전공하는 대학원생 1 명에게 오류 유형의 분류 기준을 설명한 후, 기준에 따라 분석하게 하였 다. 그 결과 오류 유형에 대한 자료의 검사자 간 신뢰도는 $96.38 \%$ 였다.

Table 2. Confrontation naming scores by groups

\begin{tabular}{lccc}
\hline & $\mathrm{NE}(\mathrm{N}=40)$ & $\mathrm{aMCl}(\mathrm{N}=35)$ & $t$ \\
\hline K-BNT & $51.30 \pm 4.01$ & $40.42 \pm 9.44$ & $6.634^{*}$ \\
Low frequency naming task & $47.25 \pm 5.43$ & $31.25 \pm 9.49$ & $9.092^{*}$ \\
\hline
\end{tabular}

Values are presented as mean \pm SD.

$\mathrm{NE}=$ normal elderly; $\mathrm{aMCl}=$ amnestic-mild cognitive impairment; $\mathrm{K}-\mathrm{BNT}=$ Korean version of Boston Naming Test (Kim \& Na, 1997).

${ }^{*} p<.001$.

\section{자료의 통계처리}

본 연구의 통계 분석은 SPSS version 22 통계 프로그램을 활용하 였다. 집단과 단어 빈도에 따른 대면이름대기과제 정반응수의 차이 를 살펴보기 위하여 반복측정 분산분석(repeated ANOVA)을 시 행하였으며. 사후 검증 시, 집단 내 단어 빈도 간 정반응수 비교는 대응표본 $t$-test를 실시하였다. 집단 간 오류 유형의 비율에 대한 비 교는 독립표본 $t$-test를 실시하였다. 또한, 단어 빈도에 따른 대면이 름대기과제 수행과 인지기능 선별검사 간의 상관관계를 살펴보기 위하여 Pearson 상관분석을 실시하였다.

\section{연구결과}

\section{집단과 대면이름대기 과제의 단어 빈도에 따른 이름대기 수행력 차이}

Table 2에 나타난 바와 같이 K-BNT와 저빈도 단어 이름대기과 제에서의 정상노인 집단, $\mathrm{aMCI}$ 집단의 대면이름대기 점수를 비교 해본 결과, $\mathrm{aMCI}$ 집단은 $\mathrm{K}-\mathrm{BNT}$ 과제 $(p<.001)$ 와 저빈도 단어 이름 대기과제 $(p<.001)$ 모두에서 정상노인 집단보다 유의하게 낮은 이

Table 3. Repeated measurement ANOVA results: confrontation naming ability by groups and word frequency

\begin{tabular}{lrrrr}
\hline & $\begin{array}{c}\text { Type III sum of } \\
\text { squares }\end{array}$ & df & Mean square & $F$ \\
\hline Between & & & & $66.775^{*}$ \\
Group & $6,735.772$ & 1 & $6,735.772$ & \\
Error & $7,363.721$ & 73 & & \\
Within & & & & \\
Frequency & $1,631.524$ & 1 & $1,631.524$ & $232.876^{*}$ \\
Frequency× Group & 244.804 & 1 & 244.804 & $34.942^{*}$ \\
Error & 511.436 & 73 & 7.006 & \\
\hline
\end{tabular}

${ }^{*} p<.001$.

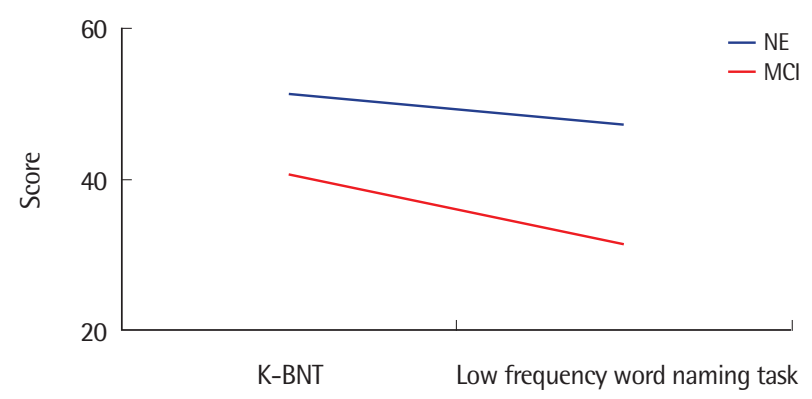

Figure 1. Interaction effect on confrontation naming scores by groups and word frequency.

$\mathrm{NE}=$ normal elderly; $\mathrm{aMCl}$ = amnestic-mild cognitive impairment; $\mathrm{K}-\mathrm{BNT}$ = Korean version of Boston Naming Test (Kim \& Na, 1997). 
Table 4. Ratio of error types in low frequency word naming task by group

\begin{tabular}{lccc}
\hline Error type & $\mathrm{NE}(\mathrm{n}=40)$ & $\mathrm{aMCl}(\mathrm{n}=35)$ & $t$ \\
\hline Visual perception & $1.90(14.24)$ & $6.23(21.47)$ & $-3.287^{*}$ \\
Semantic & $7.05(55.97)$ & $12.82(44.50)$ & $3.538^{*}$ \\
Unrelated & $.40(2.86)$ & $2.02(7.19)$ & $-3.681^{* *}$ \\
Phonological & $.57(5.29)$ & $1.77(6.25)$ & -.684 \\
Other & $2.83(21.62)$ & $5.89(20.58)$ & .345 \\
\hline
\end{tabular}

Values are presented as mean (\%).

$\mathrm{NE}=$ normal elderly; $\mathrm{aMCl}=$ amnestic-mild cognitive impairment.

${ }^{*} p<.01,{ }^{* *} p<.001$.

Table 5. The correlation coefficient among the K-MMSE scores and confrontation naming scores by word frequency in normal elderly

\begin{tabular}{lccc}
\hline & K-MMSE & K-BNT & $\begin{array}{c}\text { Low frequency } \\
\text { word naming task }\end{array}$ \\
\hline K-MMSE & 1 & & \\
K-BNT & .037 & 1 & \\
Low frequency word naming task & .200 & $.749^{*}$ & 1
\end{tabular}

K-MMSE = Korean version of Mini-Mental State Examination (Kang, Na, \& Hahn, 1997); K-BNT = Korean version of Boston Naming Test (Kim \& Na, 1997). ${ }^{*} p<.01$.

름대기 수행력을 보였다.

집단 및 단어 빈도에 따른 이름대기 수행력의 차이를 비교하기 위해 반복측정 분산분석(repeated measures ANOVA)으로 확인 한 결과(Table 3, Figure 1), 집단과 과제에 따른 이름대기 수행력 간 에 상호작용이 관찰되었다 $(F=34.942, p<.001)$. 과제별로 대응표 본 $t$-test를 시행한 결과, 정상노인 집단은 저빈도 단어 이름대기 과 제에서의 정반응수가 K-BNT 과제에 비하여 유의하게 낮게 나타났 으며 $(t=7.112, p<.001), \mathrm{aMCI}$ 집단에서도 저빈도 단어 이름대기과 제의 정반응수가 K-BNT 과제에 비하여 유의하게 낮게 나타났다 $(t=13.915, p<.001)$.

\section{저빈도 단어 이름대기 과제에서의 집단 간 오류 유형 차이}

집단 간 오류 유형별 비율의 평균값 비교를 위해 독립표본 $t$-test 를 실시하였다. 그 결과, $\mathrm{aMCI}$ 집단은 정상노인 집단 보다 시지각 오류 $(t=-3.287, p<.01)$, 의미적 오류 $(t=3.538, p<.01)$, 비연관 오류 $(t=-3.681, p<.001)$ 의 비율이 높게 나타났다. 이러한 통계분석 결 과는 Table 4 에 제시하였다.

\section{집단에 따른 인지기능과 단어 빈도별 대면이름대기과제 수행력 간 상관관계}

정상노인 집단, $\mathrm{aMCI}$ 집단의 $\mathrm{K}-\mathrm{MMSE}$ 점수와 두 가지 대면이름 대기 수행력 사이의 상관분석 결과를 Tables 5 와 6 에 제시하였다.
Table 6. The correlation coefficient among the K-MMSE scores and confrontation naming ability by word frequency in $\mathrm{aMCl}$

\begin{tabular}{lccc}
\hline & K-MMSE & K-BNT & $\begin{array}{c}\text { Low frequency word } \\
\text { naming task }\end{array}$ \\
\hline K-MMSE & 1 & & \\
K-BNT & .307 & 1 & \\
Low frequency word naming task & $.426^{*}$ & $.915^{* *}$ & 1 \\
\hline
\end{tabular}

K-MMSE = Korean version of Mini-Mental State Examination (Kang, Na, \& Hahn, 1997); K-BNT = Korean version of Boston Naming Test (Kim \& Na, 1997).

${ }^{*} p<.05,{ }^{* *} p<.01$.

$\mathrm{aMCI}$ 의 경우 K-MMSE 점수와 K-BNT 및 저빈도 단어 이름대기과 제 점수 간 정적상관이 있는 것으로 나타났으며, K-MMSE 점수와 K-BNT 점수 간 상관계수는 .307 ( $p>$.05)로 통계적 유의성이 나타 나지 않은 반면에 K-MMSE 점수와 저빈도 단어 이름대기과제의 점수 간 상관계수는 .421 $(p<.05)$ 로 통계적 유의성이 확인되었다. 정상노인의 경우 $\mathrm{K}-\mathrm{MMSE}$ 점수와 K-BNT $(r=.066, p>.05)$ 및 저 빈도 단어 이름대기 과제 $(r=.245, p>.05)$ 점수 간 통계적 유의성이 없었다.

\section{논의 및 결론}

본 연구에서는 $\mathrm{aMCI}$ 환자의 저빈도 단어 이름대기 수행력을 확 인하고 단어 빈도에 따른 이름대기 수행력이 어떠한 차이를 보이는 지를 확인하였다. 또한 전반적인 인지기능 선별검사 점수와 대면이 름대기과제(K-BNT/저빈도 단어 이름대기과제) 수행력에서의 상 관관계를 확인하였다.

먼저 집단에 따른 이름대기과제 수행력을 비교한 결과, 두 과제 모두 $\mathrm{aMCI}$ 집단의 수행력이 정상노인 집단 보다 유의하게 낮았다. 이러한 결과는 $\mathrm{MCI}$ 환자군과 정상군의 대면이름대기 능력을 비교 한 선행연구들 중 두 집단 간 유의한 차이를 확인한 일부 선행연구 의 결과와 일치한다(Balthazar et al., 2008; Duong et al., 2006; Jefferson et al., 2007; Johns et al., 2012; Mioshi et al., 2006; Woo \& $\mathrm{Kim}, 2015)$. 대면이름대기를 하기 위해서는 그림자극을 확인하고 그 대상의 용도 혹은 기능에 대한 온전한 의미 지식을 활성화시켜 그에 부합하는 적절한 어휘를 선택하여 산출하는 과정이 요구된다 (Ellis \& Young, 1988; Howard, 1985). 일반적으로 의미적 측면의 언 어능력 저하는 좌반구의 내측측두엽(medial temporal lobe)의 손 상과 관련이 있다고 알려져 있으며(Morra et al, 2009), 이는 기억과 관계된 주요 역할을 담당하는 내후각피질(entorhinal cortex)과 해 마(hippocampus)가 위치하는 영역이다. 정상 노화과정에서는 내 후각피질과 해마에서의 신경세포수가 변하지 않았지만, $\mathrm{MCI}$ 의 경 
우 내후각피질과 해마에서 정상노인보다 $36 \%$ 정도의 신경세포 손 실을 보였으며, 이로 인한 위축과 용적의 감소를 보였다(Choi, 2003; Petersen, 2003). 이러한 맥락에서 이름대기 과정에 필요한 요소인 의미기억 체계의 감퇴가 $\mathrm{MCI}$ 에서 보고되고 있으므로(Balthazar, Cendes et al., 2008; Petersen et al., 1999), 본 연구 결과에서 나타난 두 집단의 수행력 차이는 상기와 같은 신경병리적 특징과 관련된 것이라 짐작할 수 있다.

그러나 보다 흥미로운 결과는 $\mathrm{aMCI}$ 집단에서 K-BNT과제보다 저빈도 단어과제에서의 수행력이 급격히 저하되어 집단과 단어의 빈도에 따른 효과가 관찰된 것이다. 이러한 결과는 먼저 단어의 빈 도 효과(word frequency effect) (Taft, 1979)로 설명해보고자 한다. 단어 빈도 효과는 사용 빈도가 낮은 단어를 처리하는데, 빈도가 높 은 단어에 비해 더 많은 노력이 필요한 현상을 말한다. 단어 빈도의 효과가 나타나는 이유로는 자주 사용되는 고빈도 단어는 의미 체 계에 저장된 표상의 강도가 강하고 안정적이지만 평소에 자주 사 용하지 않은 저빈도 단어는 고빈도 단어에 비하여 단어에 대한 의 미적 표상의 강도가 약하기 때문이다(Gollan, Salmon, Montoya, \& da Pena, 2010). 고빈도 단어는 자극에 대한 반복적인 노출과 학습 을 통하여 의미와 어휘 및 음운을 연결하는 노드(node)가 견고해 지고 쉽게 활성화될 수 있도록 산출의 역치(threshold)가 올라와 있 는 상태이기 때문에 주변의 많은 경쟁 단어들 중에서 목표에 부합 하는 단어를 선택하는 과정이 용이하다(Jones \& Langford, 1987). 반면에 저빈도 단어는 활성화된 경험의 빈도가 적기 때문에 필요한 경우 상대적으로 약한 노드를 통하여 의미적 정보를 활성화시켜야 하며 이에 따라산출의 역치도 높지 않은 상태이므로(Burke, MacKay, Worthley, \& Wade, 1991; Harley \& Bown, 1998) 산출을 위해 더 많은 노력이 필요할 수 있다.

$\mathrm{MCI}$ 에서 빈도에 따른 수행력의 차이가 관찰된 두 번째 이유로 는 의미적 표상의 네트워크상에서 고빈도 및 저빈도 단어가 다른 단어들과 연결되어 있는 상태가 차이가 나기 때문으로 설명할 수 있겠다. 고빈도 단어는 대체로 전형적인 의미를 가진 단어일 가능 성이 높다고 가정해볼 때 목표 단어를 산출하는 과정에서 유기적 으로 얽혀있는 의미적 네트워크가 동시다발적으로 활성화될 수 있 는데, 이때 고빈도 단어의 경우에는 목표 단어와 자질들을 공유하 는 다른 단어의 다양한 경로를 통해서 목표 단어로 보다 쉽게 접근 할 수도 있다. 그러나 저빈도 단어는 비전형적인 경우가 많으므로 단어 선택 시 목표단어로 접근할 수 있는 경로가 고빈도 단어에 비 해 제한적일 수 있다.

상기에서 언급된 저빈도 단어가 가진 두 가지 제약은 앞서 언급 한 MCI단계에서부터 시작되는 의미네트워크의 감퇴(Balthazar et al., 2008; Petersen, 2003)와 맞물리게 되면서 안정적이고 풍부한 의 미 표상을 지닌 고빈도 개념에 비해 뇌의 변화에 있어서 더 민감하 게 영향을 받았을 것으로 생각된다. 보다 견고하게 저장된 정보의 경우 발병 후 뇌의 손상으로 인한 언어적 능력의 저하에도 불구하 고 그 기능이 보존될 가능성이 높다는 연구결과(Ralph, Graham, Ellis, \& Hodges, 1998)가 이를 뒷받침한다. AD 환자와 정상통제군 을 대상으로 단어 빈도에 따른 대면이름대기 수행력을 확인한 연 구(Thompson-Schill, Gabrieli, \& Fleischman, 1999)에서도 본 연 구결과와 마찬가지로 정상군은 단어 빈도에 따른 오류율에서 유의 한 통계적 차이가 없었으나 $\mathrm{AD}$ 환자군은 고빈도 단어 과제보다 저 빈도 단어 과제의 오류율이 유의하게 높았다. 이러한 결과는 저빈 도 단어의 과제가 뇌손상에 더욱 취약할 수 있음을 보여준다. 이외 에 이름대기의 질적인 측면을 확인한 선행연구(Astell \& Harley, 1996; Balota \& Chumbley, 1984)에서도 $\mathrm{AD}$ 의 경우 사용빈도가 낮 은 단어가 고빈도 단어에서보다 느린 반응속도와 낮은 정확도를 보 이는 것으로 나타났다. 따라서 K-BNT의 경우 고빈도 단어부터 저 빈도 단어까지 다양한 빈도로 구성되어 있는 반면에, 저빈도 단어 이름대기과제는 저빈도의 단어로만 구성이 되었으므로 의미 기억의 감퇴가 있는 $\mathrm{aMCI}$ 집단에서 더욱 타격을 받았을 가능성이 있겠다.

저빈도 단어 이름대기과제에서의 집단 간 오류 양상을 살펴보기 위해, 두 집단이 보인 오류를 5 가지 오류 유형 분류 기준에 따라 분 석한 결과, 정상노인 집단의 이름대기 오류 양상은 의미적 오류- 기 타 오류 - 시지각 오류 - 음운적 오류 - 비연관 오류 순으로 나타났으 며, aMCI 집단의 이름대기 오류 양상은 의미적 오류 - 시지각 오류 - 기타 오류 - 비연관 오류 - 음운 오류 순으로 나타나 두 집단 모두 의미적 오류를 빈번히 산출하였다. 이러한 결과는 두 집단 모두 어 휘를 인출하는 과정에서 정확한 목표 어휘를 선택하거나 떠올리지 못하는 경우, 목표 어휘와 관련된 의미적 정보에 의존하여 어휘를 찾으려는 경우가 많음을 시사한다(McGregor, 1997). 그러나 집단 간 오류율 비교에서 $\mathrm{aMCI}$ 집단이 비연관 오류를 유의하게 많이 보 인 결과가 흥미로운데, 이는 결국 단어를 산출하려는 전략으로서 의미적 정보를 이용하기는 하나 $\mathrm{aMCI}$ 의 경우 의미 체계 손상이 있 기 때문에(Bowles, Obler, \& Albert, 1987) 목표 어휘에 대한 개념과 특징에 대한 의미적 활성화가 정확하게 이루어지지 않아 무관한 낱말을 말하거나 무관한 설명을 하고 목표 어휘의 의미적 특성과 는 관련 없는 자신의 경험을 말하는 오류를 보인 것으로 해석할 수 있다. 두 집단의 오류 양상은 전반적으로 유사하였지만, 정상노인 집단은 의미적 오류 다음으로 기타 오류를 많이 보인 반면, aMCI 집단은 의미적 오류 다음으로 시지각 오류를 많이 보였다. 앞서 제 시한 어휘 처리과정 이론에서 살펴보면, 시지각적 오류는 그림의 
시각적 분석이 이루어지는 단계에서 사물의 속성 정보들이 통합되 어 사물로 인식하는 과정의 손상으로 인해 나타난다고 볼 수 있다. 또한 시각적 기능을 담당하는 뇌 영역의 손상으로 그림자극을 정 확하게 파악하고 대상을 재인해내는 능력이 손상되어 그림과 전혀 유사하지 않은 사물을 이야기 하는 무관 오류와 한 장면에서 한 부 분 이상을 동시에 보지 못하거나 각 부분을 전체로 통합하여 보지 못하는 전체/부분 오류 등을 보이게 된다. 신경병리적으로 시지각 적 오류는 양측 두정-후두엽(parieto-occipital lobe)의 손상에 기인 하는데(Mosimann et al., 2004), 두정-후두엽 퇴화로 인한 시지각 능력의 손상은 $\mathrm{AD}$ 초기부터 나타나며(Kim et al., 1997; Hodges, Patterson, Graham, \& Dawson, 1996), 이러한 손상의 정도는 치매 가 진행될수록 심화된다(Rizzo, Anderson, Dawson, \& Nawrot, 2000). aMCI와 $\mathrm{AD}$ 는 신경병리학적 현상의 연장선상에 있다는 점 (Petersen, 2003)을 고려하면, aMCI 집단이 정상노인 집단에 비하 여 유의하게 많은 시지각 오류 비율을 보인 본 연구의 결과를 설명 가능하다.

마지막으로, 집단에 따른 인지기능 선별검사 점수와 단어 빈도별 대면이름대기과제의 수행력 간 관계를 분석한 결과, $\mathrm{aMCI}$ 집단에 서 K-MMSE 및 K-BNT점수와 저빈도 단어 이름대기과제 수행력 간에 상관성이 관찰되었다. K-MMSE는 시간지남력, 장소지남력, 기억등록, 주의력, 계산, 기억회상, 이름대기, 명령시행, 따라말하기, 읽기, 쓰기, 시공간적 구성 등을 확인하는 항목으로 이루어져 있어 서 전반적인 인지기능을 선별적으로 확인할 수 있는 검사이다. 이 는 결국 $\mathrm{MCI}$ 의 인지기능이 정상 범주에 속한다 하더라도 인지기능 의 미세한 손상이 저빈도 단어 이름대기와 같은 어휘의미적 측면 의 언어장애와 관련이 있음을(Fonseca, Tedrus, Prandi, Almeida, \& Furlanetto, 2011) 의미한다.

본 연구결과를 종합하면, $\mathrm{MCI}$ 는 이름대기의 어려움을 보일 수 있는데 특히 정상노화에서 $\mathrm{AD}$ 로 전이되는 단계에서 관찰되는 미 묘한 변화는 보다 어려운 저빈도 단어의 이름대기과제에서 더욱 두 드러질 수 있음을 보여준다. 특정 질환에서 과제의 위계에 따른 세 분화된 임상적 프로파일을 제공하는 것은 언어장애의 진단 및 중 재에 있어서 근거기반실무의 기반을 제공한다. 따라서 임상현장에 서 널리 사용되는 표준화된 이름대기검사인 K-BNT 결과와 더불 어 본 예비연구의 결과인 저빈도단어로 구성된 이름대기과제의 수 행력이 질환의 조기예방이나 감별진단 및 중재에서 부가적으로 함 께 활용될 수 있는 가능성을 시사한다. 본 연구의 제한점은 다음과 같다. 첫째, 본 연구는 $\mathrm{aMCI}$ 만을 대상으로 하였으나 이 집단은 기 타 인지기능장애의 동반 여부에 따라 aMCI-single domain과 aMCI-multiple domain으로 다시 나뉠 수 있고, 두 집단이 보이는 이름
대기 양상은 차이가 있을 수 있다. 따라서, 후속 연구에서는 aMCI 의 하위유형에 따른 특성을 살펴볼 필요가 있겠다. 둘째, 정반응을 산출하기까지 소요되는 시간도 측정하여 분석한다면, 양적인 측면 뿐만 아니라 질적인 측면에서 이름대기장애의 특성을 확인하는데 도움을 줄 수 있을 것이다. 셋째, 본 예비연구 결과를 바탕으로 항 목을 축소 선별하고 단축화하는 작업을 거쳐 정상과 $\mathrm{MCI}$ 를 변별 할 수 있는 절단점과 진단정확도 등을 제시하면서 검사 도구의 유 용성을 검증하는 작업이 이루어져야 한다. 넷째, 오류 분석의 측면 에서 세부 유형 간의 비율에서는 집단 간 차이가 관찰되었으나 세 부 유형 내의 하위유형에 대한 통계적으로 검정은 유의미하지 않았 으므로 추후 연구에서는 오류 분석 기준을 재검토하는 과정이 필 요하다. 마지막으로, K-MMSE의 결과를 사용하였으나 K-MMSE 는 선별적 수준의 인지기능 검사이므로 전반적인 인지능력과 이름 대기과제 사이의 상관을 살펴보기 위해 다양한 종합인지검사를 통한 과제와의 상관을 살펴보는 것이 필요하겠다.

\section{REFERENCES}

Adlam, A. L. R., Bozeat, S., Arnold, R., Watson, P., \& Hodges, J. R. (2006). Semantic knowledge in mild cognitive impairment and mild Alzheimer's disease. Cortex, 42, 675-684.

Altmann, L. J., Kempler, D., \& Andersen, E. S. (2001). Speech errors in Alzheimer's disease: reevaluating morphosyntactic preservation. Journal of Speech, Language, and Hearing Research, 44, 1069-1082.

Astell, A. J., \& Harley, T. A. (1996). Tip-of-the-tongue states and lexical access in dementia. Brain and Language, 54, 196-215.

Balota, D. A., \& Chumbley, J. I. (1984). Are lexical decisions a good measure of lexical access? The role of word frequency in the neglected decision stage. Journal of Experimental Psychology: Human Perception and Performance, $10,340-357$.

Balthazar, M. L. F., Cendes, F., \& Damasceno, B. P. (2008). Semantic error patterns on the Boston Naming Test in normal aging, amnestic mild cognitive impairment, and mild Alzheimer's disease: is there semantic disruption? Neuropsychology, 22, 703-709.

Beinhoff, U., Hilbert, V., Bittner, D., Grön, G., \& Riepe, M. W. (2005). Screening for cognitive impairment: a triage for outpatient care. Dementia and Geriatric Cognitive Disorders, 20, 278-285.

Bowles, N. L., Obler, L. K., \& Albert, M. L. (1987). Naming errors in healthy aging and dementia of the Alzheimer type. Cortex, 23, 519-524.

Brookshire, K. H. (1970). Comparative psychology of learning. In M. H. Max 
(Ed.), Learning: interactions (pp. 291-364). London: Macmillan Company.

Burke, D. M., \& Shafto, M. A. (2004). Aging and language production. Current Directions in Psychological Science, 13, 21-24.

Burke, D. M., MacKay, D. G., Worthley, J. S., \& Wade, E. (1991). On the tip of the tongue: what causes word finding failures in young and older adults? Journal of Memory and Language, 30, 542-579.

Caramazza, A., \& Hillis, A. E. (1990). Where do semantic errors come from? Cortex, 26, 95-122.

Chenery, H. J., Murdoch, B. E., \& Ingram, J. C. (1996). An investigation of confrontation naming performance in Alzheimer's dementia as a function of disease severity. Aphasiology, 10, 423-441.

Choi, H. J., Kim, J. H., Lee, C. M., \& Kim, J. I. (2013). Features of semantic language impairment in patients with amnestic mild cognitive impairment. Dementia and Neurocognitive Disorders, 12, 33-40.

Choi, K. (2003). View from relationships with aging and Alzheimer's disease: neuropathology of MCI. Journal of the Korean Dementia Association, 2, 101-107.

Christensen, K. J., Multhaup, K. S., Nordstrom, S., \& Voss, K. (1991). A cognitive battery for dementia: development and measurement characteristics. Psychological Assessment: A Journal of Consulting and Clinical Psychology, 3, 168-174.

Duong, A., Whitehead, V., Hanratty, K., \& Chertkow, H. (2006). The nature of lexico-semantic processing deficits in mild cognitive impairment. Neuropsychologia, 44, 1928-1935.

Ellis, A. W., \& Young, A. W. (1988). Human cognitive neuropsychology. Hillsdale, NJ: Lawrence Erlbaum Associates.

Fonseca, L. C., Tedrus, G. M., Prandi, L. R., Almeida, A. M., \& Furlanetto, D. S. (2011). Alzheimer's disease: relationship between cognitive aspects and power and coherence EEG measures. Arquivos de neuro-psiquiatria, 69, 875-881.

Garrard, P., Maloney, L. M., Hodges, J. R., \& Patterson, K. (2004). The effects of very early Alzheimer's disease on the characteristics of writing by a renowned author. Brain, 128, 250-260.

Gollan, T. H., Salmon, D. P., Montoya, R. I., \& da Pena, E. (2010). Accessibility of the nondominant language in picture naming: a counterintuitive effect of dementia on bilingual language production. Neuropsychologia, 48, 1356-1366.

Griffith, H. R., Netson, K. L., Harrell, L. E., Zamrini, E. Y., Brockington, J. C., \& Marson, D. C. (2006). Amnestic mild cognitive impairment: diagnostic outcomes and clinical prediction over a two-year time period. Journal of the International Neuropsychological Society, 12, 166-175.

Guo, Q. H., Zhou, B., Zhao, Q. H., Wang, B., \& Hong, Z. (2012). Memory and Executive Screening (MES): a brief cognitive test for detecting mild cognitive impairment. BMC neurology, 12, 119.

Harley, T. A., \& Bown, H. E. (1998). What causes a tip-of-the-tongue state? Evidence for lexical neighbourhood effects in speech production. British Journal of Psychology, 89, 151-174.

Health Insurance Review \& Assessment Service. (2016). http://www.hira. or.kr/dummy.do?pgmid=HIRAA 020041000000

Heller, R. B., Dobbs, A. R., \& Rule, B. G. (1992). Communicative function in patients with questionable Alzheimer's disease. Psychology and Aging, 7(3), 395-400.

Hodges, J. R., Patterson, K., Graham, N., \& Dawson, K. (1996). Naming and knowing in dementia of Alzheimer's type. Brain and Language, 54, 302325.

Hodges, J. R., Salmon, D. P., \& Butters, N. (1992). Semantic memory impairment in Alzheimer's disease: failure of access or degraded knowledge? Neuropsychologia, 30, 301-314.

Howard, D. (1985). The semantic organisation of the lexicon: evidence from aphasia (Doctoral dissertation). University of London.

Hwang, J. H. (2013). Effects of word frequency and length lexical retrieval of elderly (Master's thesis). Daegu University, Daegu, Korea.

Hwang, Y. K., \& Kim, H. (2014). Utility of the Boston Naming test in differentiating between mild cognitive impairment and normal elderly: a metaanalysis. Communication Sciences \& Disorders, 19, 501-512.

Jefferson, A. L., Wong, S., Gracer, T. S., Ozonoff, A., Green, R. C., \& Stern, R. A. (2007). Geriatric performance on an abbreviated version of the Boston Naming Test. Applied Neuropsychology, 14, 215-223.

Jo, N. H. (2002). Research on frequency of using modern Korean: basic survey for vocabulary selection for Korean language study. Seoul: National Institute of Korean Language.

Johns, E. K., Phillips, N. A., Belleville, S., Goupil, D., Babins, L., Kelner, N., ... \& Duncan, H. D. (2012). The profile of executive functioning in amnestic mild cognitive impairment: disproportionate deficits in inhibitory control. Journal of the International Neuropsychological Society, 18, 541-555.

Jones, G. V., \& Langford, S. (1987). Phonological blocking in the tip of the tongue state. Cognition, 26, 115-122.

Joubert, S., Brambati, S. M., Ansado, J., Barbeau, E. J., Felician, O., Didic, M., ... \& Kergoat, M. J. (2010). The cognitive and neural expression of semantic memory impairment in mild cognitive impairment and early Alzheim- 
er's disease. Neuropsychologia, 48, 978-988.

Kang, Y. (2006). A normative study of the Korean-Mini Mental State Examination (K-MMSE) in the elderly. Korean Journal of Psychology: General, 25, 1-12.

Kang, Y., \& Na, D. L. (2003). Seoul Neuropsychological Screening Battery. Incheon: Human Brain Research \& Consulting Co.

Kang, Y., Na, D. L., \& Hahn, S. (1997). Korean version of Mini-Mental State Examination (K-MMSE). Seoul: Human Brain Research \& Consulting Co. Ki, B. S. (1996). A preliminary study for the standardization of geriatric depression scale short form-Korea version. Journal of the Korean Neuropsychiatric Association, 35, 298-306.

Kim, H. H., \& Na, D. L. (1997). Korean-Boston Naming Test (K-BNT). Seoul: Hakjisa.

Kim, H., \& Kim, S. R. (2013). Development of short form of the Korean version-the Boston Naming Test (K-BNT-15) based on item response theory. Journal of the Korea Contents Association, 13, 321-327.

Kim, H., Kim, E. Y., \& Na, D. L. (1997). Naming deficits in patients with dementia of the Alzheimer type: error analysis of Korean version-Boston Naming Test. Journal of the Korean Neurological Association, 15, 1012-1021.

Kim, Y. J., Pae, S., Park, E. S., \& Shin, J. C. (2002). A study of naming ability in preschool children. Korean Journal of Communication Disorders, 7, 1-12.

Ku, H. M., Kim, J. H., Kwon, E. J., Kim, S. H., Lee, H. S., Ko, H. J., ... \& Kim, D. K. (2004). A study on the reliability and validity of Seoul-Instrumental Activities of Daily Living (S-IADL). Journal of Korean Neuropsychiatric Association, 43, 189-199.

Martin, A., \& Fedio, P. (1983). Word production and comprehension in Alzheimer's disease: the breakdown of semantic knowledge. Brain and Language, 19, 124-141.

Mathuranath, P.S., Nestor, P.J., Berrios, G.E., Rakowicz, W., \& Hodges, J.R. (2000). A brief cognitive test battery to differentiate Alzheimer's disease and frontotemporal dementia. Neurology, 55, 1613-1620.

McGregor, K. K. (1997). The nature of word-finding errors of preschoolers with and without word-finding deficits. Journal of Speech, Language, and Hearing Research, 40, 1232-1244.

Mioshi, E., Dawson, K., Mitchell, J., Arnold, R., \& Hodges, J. R. (2006). The Addenbrooke's Cognitive Examination Revised (ACE-R): a brief cognitive test battery for dementia screening. International Journal of Geriatric Psychiatry, 21, 1078-1085.

Morra, J. H., Tu, Z., Apostolova, L. G., Green, A. E., Avedissian, C., Madsen, S. K., ... \& Schuff, N. (2009). Automated 3D mapping of hippocampal at- rophy and its clinical correlates in 400 subjects with Alzheimer's disease, mild cognitive impairment, and elderly controls. Human Brain Mapping, 30, 2766-2788.

Mosimann, U. P., Mather, G., Wesnes, K. A., O’brien, J. T., Burn, D. J., \& McKeith, I. G. (2004). Visual perception in Parkinson disease dementia and dementia with Lewy bodies. Neurology, 63, 2091-2096.

Na, D. L., \& Yoon, J. H. (in press). Difficult Naming Test.

Nebes, R. D. (1989). Semantic memory in Alzheimer's disease. Psychological Bulletin, 106, 377-394.

Petersen, R. C. (2003). Mild cognitive impairment: aging to Alzheimer's disease. London: Oxford University Press.

Petersen, R. C. (2004). Mild cognitive impairment as a diagnostic entity. Journal of Internal Medicine, 256, 183-194.

Petersen, R. C., Smith, G. E., Waring, S. C., Ivnik, R. J., Tangalos, E. G., \& Kokmen, E. (1999). Mild cognitive impairment: clinical characterization and outcome. Archives of Neurology, 56, 303-308.

Price, S. E., Kinsella, G. J., Ong, B. E. N., Mullaly, E., Phillips, M., PangnadasaFox, L., ... \& Storey, E. (2010). Learning and memory in amnestic mild cognitive impairment: contribution of working memory. Journal of the International Neuropsychological Society, 16, 342-351.

Ralph, M. A. L., Graham, K. S., Ellis, A. W., \& Hodges, J. R. (1998). Naming in semantic dementia-what matters? Neuropsychologia, 36, 775-784.

Ritchie, K., \& Touchon, J. (2000). Mild cognitive impairment: conceptual basis and current nosological status. Lancet, 355, 225-228.

Rizzo, M., Anderson, S. W., Dawson, J., \& Nawrot, M. (2000). Vision and cognition in Alzheimer's disease. Neuropsychologia, 38, 1157-1169.

Seo, S. K. (2015). Korean verbal frequency dictionary. Seoul: Hankookmunhwasa.

Taft, M. (1979). Recognition of affixed words and the word frequency effect. Memory \& Cognition, 7, 263-272.

Thompson-Schill, S. L., Gabrieli, J. D., \& Fleischman, D. A. (1999). Effects of structural similarity and name frequency on picture naming in Alzheimer's disease. Journal of the International Neuropsychological Society, 5, 659667.

Willers, I. F., Feldman, M. L., \& Allegri, R. F. (2008). Subclinical naming errors in mild cognitive impairment: a semantic deficit? Dementia \& Neuropsychologia, 2, 217-222.

Woo, H. L., \& Kim, J. W. (2015). Different cognitive profiles between mild cognitive impairment and normal elderly depending on the type of attention and naming tasks. Journal of Rehabilitation Research, 19, 297-314. 
Appendix 1. 저빈도단어 이름대기검사(DNT) 단어

\begin{tabular}{|c|c|c|c|c|c|}
\hline 번호 & 단어 & 번호 & 단어 & 번호 & 단어 \\
\hline 1 & 공작(새) & 21 & 나이테 & 41 & 기마전 \\
\hline 2 & 물레방아 & 22 & 망원경 & 42 & 분무기 \\
\hline 3 & 두레박 & 23 & 전봇대(전신주) & 43 & 죽부인 \\
\hline 4 & 절구 & 24 & 벼루 & 44 & 꽹과리 \\
\hline 5 & 낙하산 & 25 & 지문 & 45 & 방아쇠 \\
\hline 6 & 가로등 & 26 & 활주로 & 46 & 채찍 \\
\hline 7 & 맷돌 & 27 & 잠수함 & 47 & 뒤주 \\
\hline 8 & 짚신 & 28 & 안장 & 48 & 면사포 \\
\hline 9 & 비석 & 29 & 파라솔 & 49 & 처마 \\
\hline 10 & 고슴도치 & 30 & 목탁 & 50 & 각도기(분도기) \\
\hline 11 & 병풍 & 31 & 인중 & 51 & 책갈피 \\
\hline 12 & 시소 & 32 & 도리깨 & 52 & 명찰 \\
\hline 13 & 바람개비(팔랑개비) & 33 & 자판기 & 53 & 환풍기 \\
\hline 14 & 자석(지남철) & 34 & 인공위성 & 54 & 무당벌레 \\
\hline 15 & 화산(폭발) & 35 & 탈곡기 & 55 & 과녁 \\
\hline 16 & 비녀 & 36 & 아가미 & 56 & 물갈퀴 \\
\hline 17 & 악보 & 37 & 주사위 & 57 & 경첩 \\
\hline 18 & 톱니(바퀴) & 38 & 돌고래 & 58 & 미간 \\
\hline 19 & 고인돌 & 39 & 죽순 & 59 & 상모 \\
\hline 20 & 만국기 & 40 & 컴퍼스(콤파스) & 60 & 관자놀이 \\
\hline
\end{tabular}

Na \& Yoon (in press). 
Appendix 2. 저빈도단어 이름대기검사의 오류 유형 분석 기준

\begin{tabular}{|c|c|c|}
\hline 오류 유형 & & 정의 \\
\hline \multirow[t]{5}{*}{ 시지각 오류 } & 연관오류 & $\begin{array}{l}\text { 그려진 자극과 유사하게 생긴 사물로 대치 } \\
\text { 예: 시소 } \rightarrow \text { 지렛대; 자판기 } \rightarrow \text { 냉장고; 고인돌 } \rightarrow \text { 식탁 }\end{array}$ \\
\hline & 무관오류 & $\begin{array}{l}\text { 자극 그림에 대한 시각적 착오로 인해 자극과 관계없는 설명을 하는 경우 } \\
\text { 예: 인공위성 } \rightarrow \text { 나침반인가...; 물갈퀴 } \rightarrow \text { 지뢰인가... }\end{array}$ \\
\hline & 시지각오류 설명 & $\begin{array}{l}\text { 그려진 자극과 유사하게 생긴 사물 설명 } \\
\text { 예: 가로등 } \rightarrow \text { 이거 공 던지는 거; 고인돌 } \rightarrow \text { 놀이터에 가면 앉는 거 }\end{array}$ \\
\hline & 전체/부분오류 & $\begin{array}{l}\text { 그림의 일부분 또는 전체를 보고 지칭 } \\
\text { 예: 물갈퀴 } \rightarrow \text { 오리발; 명찰 } \rightarrow \text { 홍길동인데... }\end{array}$ \\
\hline & 단순묘사 & $\begin{array}{l}\text { 그림을 눈에 보이는 대로 서술하듯 설명 } \\
\text { 예: 기마전 } \rightarrow \text { 애기들이 싸움하는 거 같네; 나이테 } \rightarrow \text { 나무 동그라미인데 }\end{array}$ \\
\hline \multirow[t]{7}{*}{ 의미적 오류 } & 상위오류 & $\begin{array}{l}\text { 목표 낱말의 의미보다 상위범주의 낱말로 대치 } \\
\text { 예: 잠수함 } \rightarrow \text { 배 }\end{array}$ \\
\hline & 대등오류 & $\begin{array}{l}\text { 목표 낱말과 같은 의미범주로 대치 } \\
\text { 예: 무당벌레 } \rightarrow \text { 풍뎅이; 고슴도치 } \rightarrow \text { 두더지 }\end{array}$ \\
\hline & 연관오류 & $\begin{array}{l}\text { 목표 낱말과 연관이 있는 낱말로 대치 } \\
\text { 예: 악보 } \rightarrow \text { 노래; 벼루 } \rightarrow \text { 붓 }\end{array}$ \\
\hline & 의미적 보속 & $\begin{array}{l}\text { 목표 낱말과 의미적으로 연관되어 있으며 이전에 말했던 낱말로 대치 } \\
\text { 예: 미간 } \rightarrow \text { 인중 }\end{array}$ \\
\hline & 정확한 설명 & $\begin{array}{l}\text { 목표 낱말을 정확하게 설명 } \\
\text { 예: 기마전 } \rightarrow \text { 운동회 때, 사람들이 말 타고 싸움하는 거 }\end{array}$ \\
\hline & 부정확한 설명 & $\begin{array}{l}\text { 목표 낱말을 애매하게 설명하는 경우 } \\
\text { 예: 경첩 } \rightarrow \text { 문에다 박는 거; 자판기 } \rightarrow \text { 넣어 놓고 파는 거 }\end{array}$ \\
\hline & 기타 & $\begin{array}{l}\text { 의미적 오류이나 위의 분류에 들어가지 않는 오류 } \\
\text { 예: 파라솔 } \rightarrow \text { 비치우산; 두레박 } \rightarrow \text { 우물바가지 }\end{array}$ \\
\hline \multirow[t]{4}{*}{ 비연관 오류 } & 무관 낱말/설명 & $\begin{array}{l}\text { 목표 낱말과 관련 없는 낱말을 말하거나 설명을 하는 경우 } \\
\text { 예: 죽순 } \rightarrow \text { 등대, 탈곡기 } \rightarrow \text { 아까 그 동봉하는 거 }\end{array}$ \\
\hline & 대용어 & $\begin{array}{l}\text { 대용어의 사용으로 내용이 부적절한 경우 } \\
\text { 예: 상모 } \rightarrow \text { 이렇게 하는 건데, }\end{array}$ \\
\hline & 자기중심 & $\begin{array}{l}\text { 개인적인 경험 등에 비추어 말하는 경우 } \\
\text { 예: 주사위 } \rightarrow \text { 이거 } 00 \text { 이가 가지고 노는 건데 }\end{array}$ \\
\hline & 무관보속 & $\begin{array}{l}\text { 목표 낱말과 의미적으로 연관이 없는 이전에 말했던 낱말로 대치 } \\
\text { 예: 인중 } \rightarrow \text { 염주; 상모 } \rightarrow \text { 팔랑개비 }\end{array}$ \\
\hline \multirow[t]{4}{*}{ 음운적 오류 } & 음소착어 & $\begin{array}{l}\text { 음소적으로 } 50 \% \text { 이상 일치되게 생략, 대치, 교차 등을 보이는 경우 } \\
\text { 예: 안장 } \rightarrow \text { 완장; 경첩 } \rightarrow \text { 견채 }\end{array}$ \\
\hline & 다른 단어로 대치 & $\begin{array}{l}\text { 음소적으로 } 50 \% \text { 이상 일치되는 기존 낱말이 있는 경우 } \\
\text { 예: 주사위 } \rightarrow \text { 주사기 }\end{array}$ \\
\hline & 비단어 & $\begin{array}{l}\text { 실제 없는 단어로 목표 낱말과 } 50 \% \text { 미만으로 음소가 일치되는 경우 } \\
\text { 예: 상모 } \rightarrow \text { 앵애 }\end{array}$ \\
\hline & 기타 & $\begin{array}{l}\text { 음운적 오류이나 위의 분류에 들어가지 않는 오류를 보이는 경우 } \\
\text { 예: 죽부인 } \rightarrow \text { 죽....; 고인돌 } \rightarrow \text { 무슨 돌 }\end{array}$ \\
\hline \multirow[t]{3}{*}{ 기타 오류 } & DK(Don’t Know) & ‘모르겠다’고 반응하는 경우 \\
\hline & NR(No Response) & 무반응을 보이는 경우 \\
\hline & 기타 & $\begin{array}{l}\text { 외국어로 답하는 경우 등 위의 분류에 들어가지 않는 오류를 보이는 경우 } \\
\text { 예: 안장 } \rightarrow \text { saddlle }\end{array}$ \\
\hline
\end{tabular}

Kim, Pae, Park, \& Shin (2002), Kim, Kim, \& Na (1997), Balthazar, Cendes, \& Damasceno (2008)에서 인용, 연구자 부분 수정. 


\section{국문초록}

\section{단어 빈도에 따른 기억성 경도인지장애 환자의 대면이름대기 특성: 예비연구}

\section{원새롬 ${ }^{1}$ 윤지혜 ${ }^{2} \cdot$ 나덕렬 $^{3}$}

1한림대학교 대학원 언어병리학과, ${ }^{2}$ 한림대학교 언어청각학부, ${ }^{3}$ 성균관의대 삼성서울병원 신경과

배경 및 목적: 본 연구에서는 $\mathrm{aMCI}$ 환자를 대상으로 단어 빈도에 따른 대면이름대기과제 수행력과 오반응 특성을 살펴보고 전반적인 인지능력과 대면이름대기 수행력 간의 관계를 확인하였다. 방법: 정상노인 40 명과 $\mathrm{aMCI}$ 환자 35 명을 대상으로 K-BNT와 저빈도 단어 이름대기과제를 시행하였다. 먼저, 두 집단 간 이름대기과제의 수행력의 차이를 확인하였고, 두 집단 간 저빈도 단어 이름대기과제에서 관찰된 오류 유형을 비교하였다. 또한, K-MMSE 점수와 K-BNT 점수 및 저빈도 단어 이름대기과제의 점수 간의 상관관계를 분석하였 다. 결과: 첫째, $\mathrm{aMCI}$ 집단이 정상노인 집단보다 모든 과제에서 유의하게 낮은 수행력을 보였다. 두 집단 모두 K-BNT보다 저빈도 단어 이름대기 과제에서 더 낮은 점수를 보였지만, 이러한 수행의 차이는 $\mathrm{aMCI}$ 집단에서 유의미하게 관찰되었다. 둘째, $\mathrm{aMCI}$ 집단이 의미적 오류, 시지각오류, 비연관 오류에서 유의하게 높은 비율을 보였다. 셋째, aMCI 집단에서 K-MMSE 점수와 저빈도 단어 이름대기 점수 간의 상관성이 관찰되었다. 논의 및 결론: 고빈도 단어는 의미 체계에 저장된 표상의 강도가 강하고 안정적이지만 저빈도 단어는 고빈 도 단어에 비하여 단어에 대한 의미적 표상의 강도가 약하기 때문에 $\mathrm{aMCI}$ 의 뇌신경학적 변화에 더 민감하게 영향을 받을 수 있다. 임상 적 적용의 측면에서 저빈도 단어 이름대기과제는 $\mathrm{aMCI}$ 집단의 저하된 기능을 확인하고감별하는데 도움을 줄수 있다.

핵심어: 경도인지장애, 대면이름대기, 저빈도 단어

이 논문은 2017년도 한림대학교 교비연구비(HRF-201704-011)에 의하여 연구되었음.

이 논문은 2017년 정부(산업통상자원부)의 재원으로 한국산업기술평가관리원의 지원을 받아 수행된 연구임(과제번호 10063384). 본 연구는 2014년 정부(교육부)의 재원으로 한국연구재단의 지원을 받아 수행된 연구임(NRF-2014S1A5A2A03065709).

\section{참고문헌}

강연욱(2006). K-MMSE (Korean-Mini Mental State Examination)의 노인 규준 연구. 한국심리학회지: 일반, 25, 1-12.

김유정, 배소영, 박은숙, 신지철(2002). 학령전기 아동의 이름대기 특성 연구. 언어청각장애연구, 7, 1-12.

김향희, 김수련(2013). 문항반응이론을 적용한 한국판 보스톤 이름대기 검사 단축형(K-BNT-15) 개발. 한국콘텐츠학회지, 13, 321-327.

김향희, 김은연, 나덕렬(1997). 알쯔하이머성 치매환자의 이름대기 장애: 한국판 보스톤 이름대기검사상의 오류를 중심으로. 대한신경과학회지, 15 ,

1012-1021.

김향희, 나덕렬(1997). 한국판 보스톤 이름대기 검사. 서울: 학지사.

도세록, 신은숙(2012). 노인의 의료이용 증가와 시사점. 보건·복지 Issue \& Focus, 167, 1-8.

서상규(2015). 한국어 구어 빈도 사전. 서울: 한국문화사

우희림, 김정완(2015). 주의력 및 이름대기 과제 유형에 따른 경도인지장애 노인의 수행 프로파일. 재활복지, 19, 297-314.

조남호(2002). 현대 국어 사용 빈도 조사: 한국어 학습용 어휘 선정을 위한 기초조사. 서울: 국립국어연구원.

최경규(2003). 인지기능장애의 신경병리-노화, 알쯔하이머병과의 관계를 중심으로. 대한치매학회지, 2, 101-107.

최현주, 김지현, 이창민, 김재일(2013). 기억형 경도인지장애환자의 의미적 측면에서의 언어장애특성. 대한치매학회지, 12, 33-40.

황윤경, 김향희(2014). 경도인지장애 변별을 위한 보스턴 이름대기 검사의 유용성. 언어청각장애연구, 19, 501-512.

황재호(2013). 단어의 빈도와 길이가 노인의 어휘인출에 미치는 영향. 대구대학교 대학원 석사학위논문. 